\title{
Case Report: Congenital absence of uvula and trismus - a rare presentation of Van der Woude syndrome [version 1; peer
} review: 2 approved with reservations]

\author{
Victoria Geraldo, Abdallah Assaf(D), Muaz Assaf, Sohiub Assaf(D), \\ Arshdeep Chauhan (D), Ramzi Ibrahim
}

Department of Pediatrics, Mount Sinai Hospital, Chicago, IL, 60608, USA

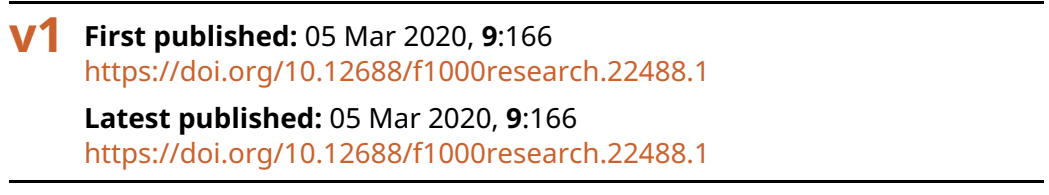

\section{Abstract}

Van der Woude syndrome (VWS) is the most common single gene mutation causing cleft lip/palate, responsible for approximately $2 \%$ of all cases. Inherited in an autosomal dominant pattern, VWS occurs at an incidence of 1 in 35,000 to 100,000. The most commonly reported manifestations of VWS is lip pits, cleft lip or palate. We present a case of a 34-week infant with unique and rarely reported symptoms of VWS, such as trismus and absent uvula.

\section{Keywords}

Van der Woude syndrome, autosomal dominant, gene, genetics, family history, congenital, lip pits, VWS, trismus, infant

Open Peer Review
Approval Status ?
of Science and Technology, Kumasi, Ghana
Children's Hospital, Kallang, Singapore
Any reports and responses or comments on the
article can be found at the end of the article.


Corresponding author: Arshdeep Chauhan (arshdeepchauhan@mail.rossmed.edu)

Author roles: Geraldo V: Conceptualization, Data Curation, Formal Analysis, Investigation, Methodology, Project Administration, Resources, Supervision, Validation, Visualization, Writing - Original Draft Preparation, Writing - Review \& Editing; Assaf A:

Conceptualization, Data Curation, Investigation, Methodology, Project Administration, Validation, Visualization, Writing - Original Draft Preparation, Writing - Review \& Editing; Assaf M: Conceptualization, Data Curation, Formal Analysis, Investigation, Methodology, Project Administration, Validation, Visualization, Writing - Original Draft Preparation, Writing - Review \& Editing; Assaf S: Conceptualization, Data Curation, Formal Analysis, Investigation, Methodology, Visualization, Writing - Original Draft Preparation, Writing - Review \& Editing; Chauhan A: Conceptualization, Data Curation, Formal Analysis, Investigation, Methodology, Supervision, Validation, Writing Original Draft Preparation, Writing - Review \& Editing; Ibrahim R: Data Curation, Formal Analysis, Investigation, Methodology, Project Administration, Visualization, Writing - Original Draft Preparation, Writing - Review \& Editing

Competing interests: No competing interests were disclosed.

Grant information: The author(s) declared that no grants were involved in supporting this work.

Copyright: (C) 2020 Geraldo V et al. This is an open access article distributed under the terms of the Creative Commons Attribution License, which permits unrestricted use, distribution, and reproduction in any medium, provided the original work is properly cited.

How to cite this article: Geraldo V, Assaf A, Assaf M et al. Case Report: Congenital absence of uvula and trismus - a rare presentation of Van der Woude syndrome [version 1; peer review: 2 approved with reservations] F1000Research 2020, 9:166 https://doi.org/10.12688/f1000research.22488.1

First published: 05 Mar 2020, 9:166 https://doi.org/10.12688/f1000research.22488.1 


\section{Introduction}

Van der Woude syndrome (VWS) is the most common single gene cause of cleft lip/palate that has been reported. First described by French Surgeon Jean Nicolas Demarquay in 1845, VWS is a rare autosomal dominant condition with a frequency of 1 in 35,000 to $100,000^{1-3}$. The clinical presentation of VWS has been well described in the literature via large multigenerational kindred studies. The most common manifestation and the cardinal feature of VWS is lip pits. This feature is present in approximately $88 \%$ affected individuals, and is the only clinical manifestation in $64 \%$ of reported cases ${ }^{4}$. Cleft lip or palate are the only other major hallmark with an estimated occurrence of $20 \% \%^{4}$. Additional reported signs of VWS are hypodontia, mucous secretion of pits, syngnathia and abnormal brain structure development ${ }^{5-7}$.

We present a case of VWS with historically undescribed findings of absent uvula and trismus. We also elaborate on recommendations for managing a newborn that presents with respiratory distress secondary to these pathological findings.

\section{Case presentation}

A female infant, born at 34-weeks gestation, was delivered via normal spontaneous vaginal delivery to a 20-year-old G3P1011 mother that presented to the Neonatal Intensive Care Unit with worsening respiratory distress. The mother received standard prenatal care and had an unremarkable gestational course. Family history revealed submucosal cleft palate and lip pits in the patient's mother. Maternal family history was significant for increased incidence of cleft lip/palate, as well as lip pits in multiple relatives (Figure 1). Paternal history/family history were insignificant.
General examination revealed the newborn patient in obvious physical and respiratory distress with copious mucous secretions near the oral orifice (Figure 2). Directed HEENT examination exposed two paramedian indentations with surrounding mound-like elevations exuding mucus located on the lower lip (Figure 3).

Visualization of the oropharynx was limited due to trismus; however, it revealed high arching sub-mucosal cleft palate and absence of a uvula (Figure 4). Directed pulmonary examination revealed substernal as well as intercostal retractions with shallow breathing and sounds indicating upper airway obstruction upon auscultation. The remainder of the physical examination was unremarkable.

Head ultrasound revealed no paramedial structural abnormalities from the high arching and submucosal cleft palate. Chest x-ray revealed mild granularity of lung fields bilaterally slightly more prominent in the right medial lung. Possibility of respiratory distress syndrome or neonatal pneumonia were not excluded.

Hospital course was complicated by apneic and desaturation episodes resulting in $\mathrm{SpO} 2$ of $<88 \%$, requiring intubation and high flow nasal cannula at $4 \mathrm{~L}$. Initially thought to be related to prematurity, the poor response and declining respiratory status raised concern and prompted us to investigate further. Aspiration of mucus that was produced within the pitting of the lips seemed to be the culprit to this patient's respiratory distress. This was further supported by the fact that the patient had an improvement in respiratory status within the decubitus and prone positions versus when the patient was supine.

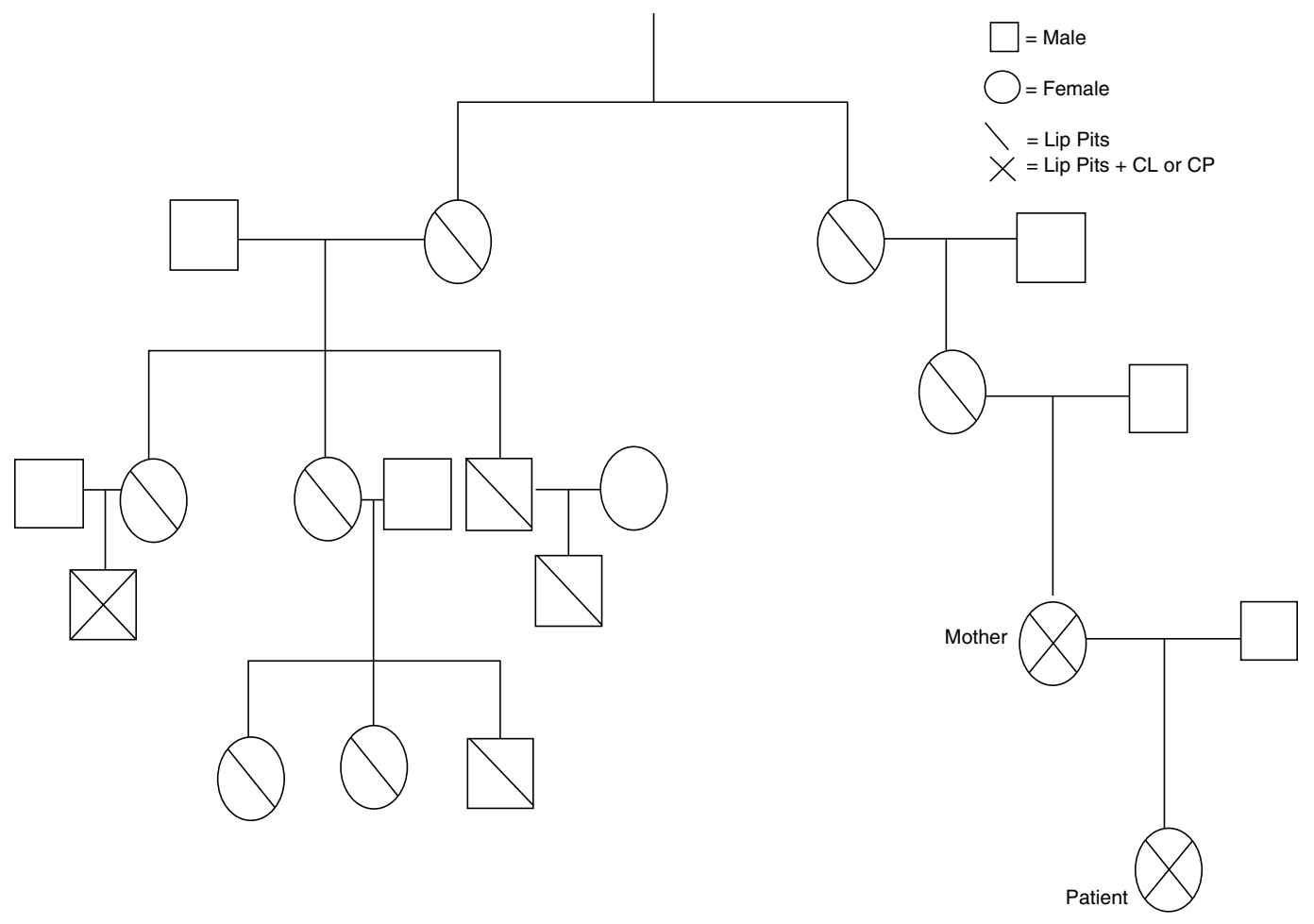

Figure 1. Patient's family tree, showing multiple relatives with similar findings. 


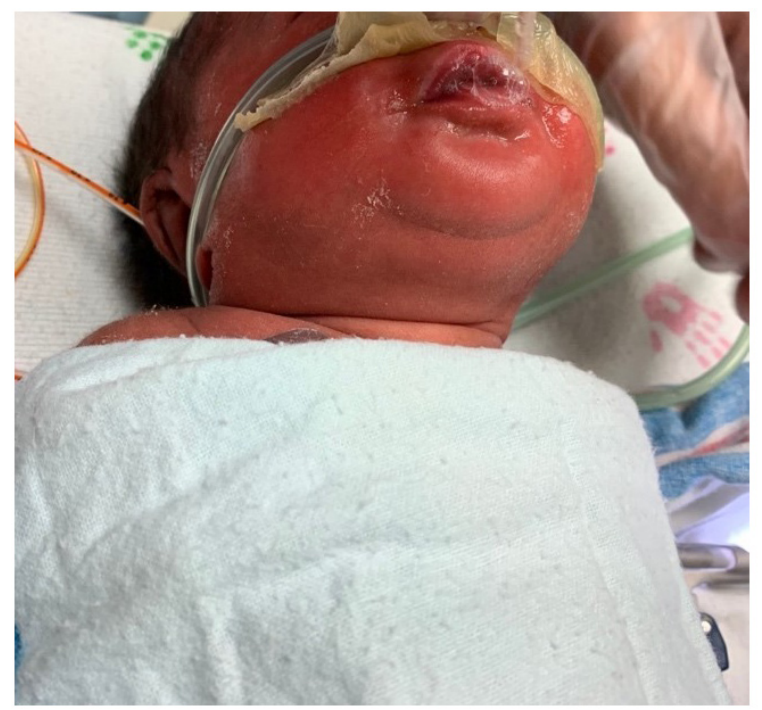

Figure 2. Copious salivary mucus production near oral orifice.

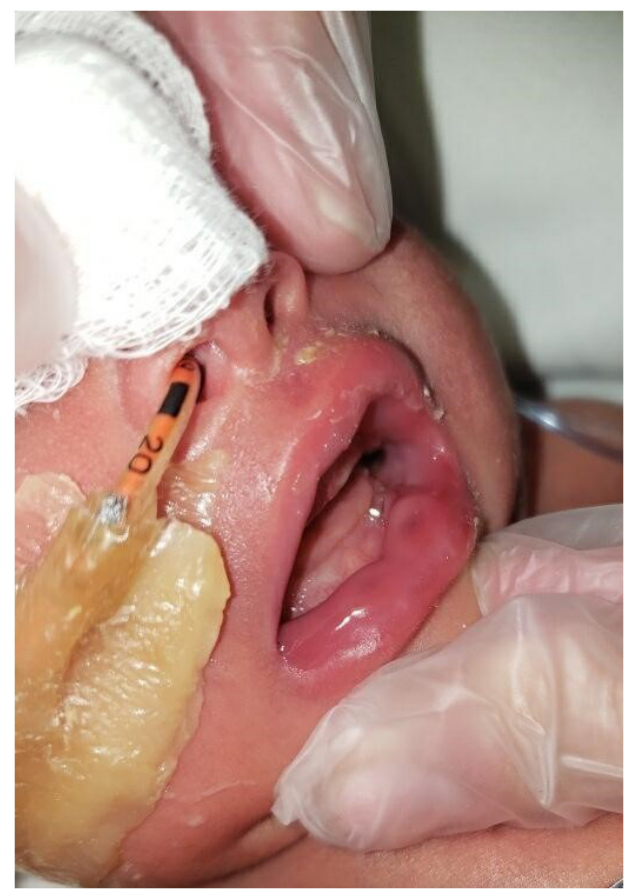

Figure 3. Indurated lip pits found on physical exam.

The course was further complicated by limitation of oral feeds due to the infant's inability to adequately open mouth from underlying trismus. This complication was addressed with nasogastric tube placement to aid in food delivery and frequent speech therapy consultations.

The patient was sent for evaluation by ENT to an outside hospital with three main treatment goals: excision of lip pits to stop

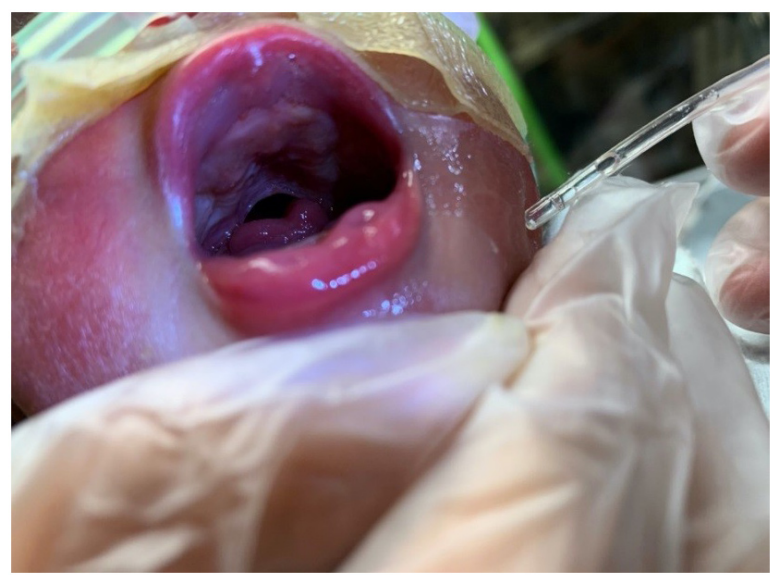

Figure 4. High arching and submucosal cleft palate, showing absent uvula.

mucus secretions and aid in respiratory status, resolution of trismus to aid with initiation of oral feeds and removal of nasogastric tube, and evaluation and repair of submucosal cleft palate.

\section{Discussion}

In an infant presenting with absent uvula or trismus it is important to keep VWS on the differential. It is the largest syndromic cause, making up almost $2 \%$ of all cases of orofacial clefts ${ }^{8}$. Furthermore, when evaluating VWS it is vital to take anticipatory steps in terms of treatment and patient guidance to avoid complications or unwanted outcomes.

In terms of anticipatory guidance, physicians should emphasize the importance of seeking early orthodontic care and speech therapy to the patient or their caregiver. Seeking orthodontic care and beginning treatment as early as 3 years old has been shown to vastly improve aesthetic outcomes compared to initiating treatment at a later age ${ }^{9}$. Early speech therapy is a necessary intervention in those with VWS. It has been reported that those with VWS have higher rates of need for speech therapy by age ten than those with non-syndromic cleft lip/palate. It has also been found that those with VWS are twice as likely to undergo procedures to correct their speech problems caused by velopharyngeal dysfunction than those with non-syndromic cleft lip and palate ${ }^{10}$. With our patient, we initiated inpatient speech therapy consultations to aid with oral feeding, which was imperative in establishing a basis toward patient well-being.

In terms of treatment, physicians should take early intervention with a multidisciplinary approach. Consultations with appropriate surgical specialties regarding excisions and specifically vertical wedge excisions of lip pits can lead to a good aesthetic outcome as well as avoid complications such as mucocele and pit recurrence ${ }^{11,12}$. In our case the team felt surgical intervention was necessary to treat and prevent future aspiration-induced respiratory compromise, as seen in the patient. 


\section{Conclusion}

VWS can present with an absent uvula and trismus, features that can potentially complicate the hospital course of an infant and impair speech development as the infant ages. Accurate diagnosis of syndromic vs non-syndromic cleft lip and palate can guide treatment. Anticipatory treatment and patient guidance can affect patient outcomes for those with VWS.

\section{Consent}

Written informed consent for the publication of the case report including any associated images was obtained from the parents of the patient.

\section{Data availability}

All data underlying the results are available as part of the article and no additional source data are required.

\section{Acknowledgments}

The authors would like to thank and acknowledge the mother of the child for allowing and trusting us to provide new information to the medical field, while trusting us to keep their personal information private.
1. Demarquay JN: Quelques considerations sur le bec-de-lievre. Gaz Med Paris 1845. Reference Source

2. Van Der Woude A: Fistula labii inferioris congenita and its association with cleft lip and palate. Am J Hum Gene. 1954; 6(2): 244-56. PubMed Abstract | Free Full Text

3. Gorlin RJ, Cohen MM Jr, Hennekam RCM: Orofacial clefting syndromes: common syndromes. In: Motulsky AG Bobrow M Harper PS Scriver C eds. Syndromes of the head and neck. 4th edn. New York: Oxford University Press. 2001. Reference Source

4. Janku $P$, Robinow $M$, Kelly $T$, et al.: The van der Woude syndrome in a large kindred: variability, penetrance, genetic risks. Am J Med Genet. 1980; 5(2) 117-123.

PubMed Abstract | Publisher Full Text

5. Advani S, Sogi S, Hugar S, et al:: Vander Woude's syndrome: The rarest of the rare. Contemp Clin Dent. 2012; 3(Suppl 2): S191-S193. PubMed Abstract | Publisher Full Text | Free Full Text

6. Puvabanditsin S, Garrow E, Sitburana O, et al:: Syngnathia and Van der Woude syndrome: a case report and literature review. Cleft Palate Craniofac J. 2003; 40(1): 104-106.

PubMed Abstract | Publisher Full Text
7. Nopoulos P, Richman L, Andreasen N, et al:: Abnormal brain structure in adults with Van der Woude syndrome. Clin Genet. 2007; 71(6): 511-517. PubMed Abstract | Publisher Full Text

8. Angiero F, Farronato D, Ferrante F, et al:: Clinical, histomorphological and therapeutic features of the Van der Woude Syndrome: literature review and presentation of an unusual case. Eur J Paediatr Dent. 2018; 19(1): 70-73. PubMed Abstract | Publisher Full Text

9. Suda N, Takada J, Ohyama K, et al.: Orthodontic treatment in a patient with Van der Woude's syndrome. Am J Orthod Dentofacial Orthop. 2006; 129(5): 696-705. PubMed Abstract | Publisher Full Text

10. Kitchin S, Grames L, Naidoo SD, et al.: Surgical, Speech, and Audiologic Outcomes in Patients With Orofacial Cleft and Van der Woude Syndrome. J Craniofac Surg. 2019; 30(5): 1484-1487.

PubMed Abstract | Publisher Full Text | Free Full Text

11. Peralta-Mamani M, Terrero-Pérez Á, Dalben G, et al.: Treatment of lower lip pits in Van der Woude syndrome: a systematic review. Int J Oral Maxillofac Surg. 2018; 47(4): 421-427.

PubMed Abstract | Publisher Full Text

12. Souto, LRM: Congenital Bilateral Lower Lip Pits Associated with Fistulae of the Minor Salivary Glands: Case Report of the Principal Van Der Woude Syndrome's Trait. Aesth Plast Surg. 2008; 32(1): 172-174. PubMed Abstract | Publisher Full Text 


\section{Open Peer Review}

\section{Current Peer Review Status: ? ?}

\section{Version 1}

Reviewer Report 14 September 2020

https://doi.org/10.5256/f1000research.24819.r70441

(C) 2020 Tan E. This is an open access peer review report distributed under the terms of the Creative Commons Attribution License, which permits unrestricted use, distribution, and reproduction in any medium, provided the original work is properly cited.

\section{Ene-Choo Tan}

KK Women's and Children's Hospital, Kallang, Singapore

Introduction: The data cited in the third and fourth statements in the first paragraph are from a case report of a single kindred published 40 years ago. The frequencies of the specific presentations (which might be specific to this family whose members likely shared the same pathogenic variant) should not be extended to the population of all patients with VWS, unless analysis is done of a large number of cases documented to date.

Family history: How was the information obtained? Were the family members examined and confirmed to be affected as recorded in the pedigree? Was it based on medical records? Or as reported by the mother? For those with $\mathrm{CL} / \mathrm{CP}$, do/did they have unilateral or bilateral types?

Case presentation: G3P1011 and HEENT should be defined.

The $3^{\text {rd }}$ sentence stated "Family history revealed submucosal cleft palate and lip pits in the patient's mother". Did the mother say that? Was she examined?

No mention was made of surgical treatment carried out and post-surgical outcome, and progress made by the infant at 1-month and 3-months.

Discussion: Replace the word "largest" in the 2nd sentence "It is the largest syndromic cause......." Orthodontic care should start before one year for patients with cleft palate, not 3 years old. Is this the first ever finding of absence of uvula and trismus? Does it add anything to the pathway of pattern formation during embryonic development?

Is the background of the case's history and progression described in sufficient detail? Partly

Are enough details provided of any physical examination and diagnostic tests, treatment given and outcomes?

Partly 
Is sufficient discussion included of the importance of the findings and their relevance to future understanding of disease processes, diagnosis or treatment?

Partly

Is the case presented with sufficient detail to be useful for other practitioners?

Partly

Competing Interests: No competing interests were disclosed.

Reviewer Expertise: Human genetics

I confirm that I have read this submission and believe that I have an appropriate level of expertise to confirm that it is of an acceptable scientific standard, however I have significant reservations, as outlined above.

Reviewer Report 06 May 2020

https://doi.org/10.5256/f1000research.24819.r62289

(C) 2020 Adu E. This is an open access peer review report distributed under the terms of the Creative Commons Attribution License, which permits unrestricted use, distribution, and reproduction in any medium, provided the original work is properly cited.

\section{Emmanuel Adu}

Department of Surgery, School of Medical Sciences, Kwame Nkrumah University of Science and Technology, Kumasi, Ghana

\section{Key Words}

Only the following can be considered key words:

Van der Woude, congenital lip pits, autosomal dominant, trismus, absent uvula

\section{Case Presentation}

1. Abbreviations used must be explained e.g. HEENT, G3P1011

2. "Trismus" is a very important finding yet it was described and also not demonstrated in the picture. Trismus was mentioned because it was limiting visualisation of the oropharynx. No muscle is in spasm, preventing mouth opening. What is being described as trismus is actually syngnatia, a condition caused by fibrous or bony adhesions between the mandible and the maxilla, which is rare finding in patients with Van der Woude syndrome( Ref. No.6).

3. The patient has a high arching submucosal cleft palate and an absent uvula. The uvula is absent because the soft palate is also cleft. In a cleft of the soft palate the uvula is absent. It can be recreated only at surgery.

\section{Discussion}

1. In the discussion of the neonate with cleft palate with respiratory obstruction and whose respiratory distress improves when nursed in the prone position, the differential diagnosis 
should not be limited to Van der Woude syndrome. The Pierre Robin Syndrome (sequence) is the first to be considered. These patients have micrognatia (small chin), glossoptosis, cleft palate and neo-natal respiratory obstruction.

2. Speech therapy by age ten is too late. Speech development begins at six months of age. Speech therapy should start by age one

3. No mention was made as to the surgical correction of the submucous cleft palate and uvula which is more likely to cause speech problems.

4. The title of the paper should read:

Van de Woude Syndrome with syngnathia: a rare presentation

Is the background of the case's history and progression described in sufficient detail? Partly

Are enough details provided of any physical examination and diagnostic tests, treatment given and outcomes?

Partly

Is sufficient discussion included of the importance of the findings and their relevance to future understanding of disease processes, diagnosis or treatment? No

Is the case presented with sufficient detail to be useful for other practitioners? Partly

Competing Interests: No competing interests were disclosed.

I confirm that I have read this submission and believe that I have an appropriate level of expertise to confirm that it is of an acceptable scientific standard, however I have significant reservations, as outlined above. 
The benefits of publishing with F1000Research:

- Your article is published within days, with no editorial bias

- You can publish traditional articles, null/negative results, case reports, data notes and more

- The peer review process is transparent and collaborative

- Your article is indexed in PubMed after passing peer review

- Dedicated customer support at every stage

For pre-submission enquiries, contact research@f1000.com 